\title{
An Investigation of Pleuropneumonia-like Organisms Isolated from the Bovine Genital Tract
}

\author{
By D. G. FF. EDWARD \\ The Wellcome Veterinary Research Station, Frant, Sussex
}

SUMMARY: Two members of the pleuropneumonia group, provisionally called the $P$ and $S$ species, were isolated from the genital tract of cattle.

The $\mathbf{P}$ strains required serum for artificial cultivation. Cultures on horse serum media had a characteristic appearance, due to the precipitation of a substance, probably protein; this aided identification. Strains differed antigenically, although common antigens were sometimes shared; antisera were prepared in rabbits against three different serological types. Agglutinins for $\mathbf{P}$ strains were not found in sera of infected cattle. There is some evidence that these strains may be capable of causing an inflammation of the genital tract which predisposes to infertility.

The S strains resembled the saprophytic members of the pleuropneumonia group, to which they were serologically related; they grew at room temperature and on media devoid of serum. They were antigenically distinct from $P$ strains. They may be commensals or gain access to discharges as contaminants.

The observations in cattle suggest further study of strains of pleuropneumonia-like organisms isolated from the human genital tract. The assessment of their pathogenicity for man may be complicated by the presence of more than one species in the human genital tract.

Since the finding of pleuropneumonia-like organisms in the genital tract of cattle was first reported (Edward, Hancock \& Hignett, 1947) investigations have been made to assess their significance and to determine whether they may be a cause of infection of the genital tract and consequently of infertility. In the course of these investigations the isolation and maintenance in subculture of a number of strains of pleuropneumonia-like organisms have provided information concerning their properties. It was apparent that there were at least two species among strains isolated from the genital tract of cattle. They differed in a number of respects, the most striking difference being that, whereas one type needed for growth in artificial culture a medium enriched by serum or ascitic fluid, the other grew well on media devoid of serum. All members of the pleuropneumonia group, previously isolated from animals or from cultures of other bacteria and including the known pathogens, have needed serum for growth in artificial culture. Only the 'saprophytic' strains, isolated by Laidlaw \& Elford (1936) from sewage and by Seiffert $(1937 a, b)$ from soil and decaying vegetable matter, could be grown on a serum-free medium. This paper records observations, including the results of a serological investigation, made on a number of strains isolated from the bovine genital tract.

\section{TECHNICAL METHODS}

The methods used for the isolation of pleuropneumonia-like organisms from the genital tract of cattle have already been described in detail (Edward et al. 1947). The semen of bulls and the vaginal mucus of cows were cultured on selective 
media. Isolations were made from single colonies; as a routine, strains were subcultured at weekly intervals on solid media, the plates being incubated for 2-3 days and then stored at $4^{\circ}$ for the remainder of the week. As a precaution against loss each strain was also maintained by weekly subculture in a semisolid medium (0.3\% agar).

The media employed were described by Edward (1947). To a basal medium prepared from ox-heart infusion broth with the addition of $1 \%$ peptone, $10 \%$ yeast extract and $20 \%(v / v)$ horse serum were added, the reaction being finally adjusted to $\mathrm{pH} \mathrm{8.0}$. Penicillin (2 drops of a solution containing $1000 \mathrm{u} . / \mathrm{ml}$. spread over half a plate of solid medium and $100 \mathrm{u} . / \mathrm{ml}$. added to a semi-solid medium) and thallium acetate (1/8000 in solid media and 1/2000 in semi-solid and fluid media) were used to inhibit the growth of other bacteria. For special purposes human ascitic fluid $(20 \%, v / v)$ and rabbit serum $(10 \%, v / v)$ replaced horse serum.

Dienes $(1947 a, b)$ claimed that under the action of penicillin pleuropneumonialike organisms could develop from cultures of other bacteria, particularly Haemophilus influenzae. In the present investigation there was no evidence that the strains isolated originated from the use of penicillin in the selective medium. For primary isolation a specimen was spread over the whole of a plate, only half of which had been previously treated with penicillin. Colonies of pleuropneumonia-like organisms appeared on the untreated half as well as on the treated side, except where the untreated half was overgrown by other bacteria.

Preparation of antigens. Cultures were made in the special broth, enriched with $20 \%(\mathrm{v} / \mathrm{v})$ human ascitic fluid and containing $1 / 2000$ thallium acetate; approximately $200 \mathrm{ml}$. of medium was inoculated with a piece of agar from a young plate culture on an ascitic fluid medium. After incubation for a number of days until growth was maximal, the cultures were centrifuged (angle centrifuge, $60 \mathrm{~min}$. at 4000 r.p.m.) and the deposit was washed once by suspending in saline and recentrifuging. For agglutination the deposit was finally suspended in buffered formol saline (Klieneberger, 1938), the suspension having an opacity half that of a Brown's tube no. 1 (Burroughs, Wellcome and Co.). Uniform and relatively stable suspensions were readily obtained; occasionally low-speed centrifugation for a few minutes was necessary to get rid of a few large clumps.

For complement-fixation tests the washed deposit of organisms was suspended in normal saline containing $1 / 1000$ merthiolate, the dilution in the first place being such that the suspension had an opacity equal to Brown's tube no. 2.

Preparation of rabbit antisera. To avoid inducing in the rabbit antibodies to foreign serum protein, all cultures used for immunization were grown in broth enriched with rabbit serum only. Unfortunately, most strains, after isolation and maintenance on media containing horse serum, at first grew poorly, or not at all, on media made with rabbit serum; gradual adaptation was necessary. A strain was first grown on a medium containing $10 \%(v / v)$ rabbit serum and $2 \%(v / v)$ horse serum. When growth was established the proportion of horse 
serum in the medium was diminished until it could be omitted. It was only after prolonged subculture, 2 or 3 times a week for weeks or months, that adequate growth was obtained in $10 \%(v / v)$ rabbit serum broth.

The growth, after centrifugation and resuspension in saline, was injected intravenously. Between 5 and 10 doses, using the deposits from a total of 0.5-1.0 1. of culture, were necessary before sufficiently high titres of antibodies developed. It was usual to inject a rabbit on each of two successive days and then to wait 7 to 10 days before giving another two injections. The health of the rabbits was unaffected by the inoculations of the living cultures.

Agglutination test. The tests were made in Dreyer's tubes, containing $0.1 \mathrm{ml}$. of successive two-fold dilutions of serum and 0.1 ml. of suspension. Agglutination was read after 4 and $6 \mathrm{hr}$. in the water bath at $52-56^{\circ}$. It was easily seen by the naked eye when the tubes were examined in a dark room with a bright light. The end-point of the titration was confirmed using a hand lens. This technique proved to give the best results after other methods had been tried. Incubation at $37^{\circ}$ in the water bath was effective for some antigens, but others were not completely agglutinated at this temperature. Allowing the tubes to stand at room temperature overnight before the final reading (Klieneberger, 1938) resulted in a non-specific clumping on the sides of the tubes which made reading difficult. Suspensions differed in the case with which they were agglutinated and in the type of clumping. Well-marked prozones up to a dilution of 1/64 sometimes occurred with high-titre sera. In all the tests controls with saline and normal rabbit serum were included.

Complement-fixation test. The tests were made in $2 \frac{3}{4} \times \frac{3}{8}$ in. tubes using unit volumes of $0.125 \mathrm{ml}$. In the test proper 1 vol. of antigen and 2 vol. of complement were added to 1 vol. of serum dilution. After incubation for $2 \mathrm{hr}$. at $37^{\circ}, 2$ vol. of sensitized sheep red cell suspension (3\% suspension of washed cells mixed $30 \mathrm{~min}$. previously with an equal volume of saline containing 12 M.H.D./ml. of haemolysin) were added and the tests read after further incubation for $1 \mathrm{hr}$. Guinea-pig serum preserved by Richardson's method (1941) was the source of complement. It was titrated with saline and with each antigen separately using the same volumes as in the test proper. Little difficulty was experienced with anti-complementary antigens. For the tests $1 \frac{1}{2}$ doses of complement were used, 1 dose being the smallest amount giving complete haemolysis in the preliminary titration with that particular antigen. In the performance of every test and titration adequate control tubes were included. Rabbit and bovine sera were inactivated by heating to $62^{\circ}$ for $30 \mathrm{~min}$.

The optimum dilution for each antigen was estimated, using its homologous serum or some other rabbit antiserum with which it fixed complement. A series of titrations of serum were put up using different dilutions of antigen, namely, 1/1, 1/2,1/4 and 1/8. It was found that whereas some antigens needed no dilution, others gave higher serum titres when diluted $1 / 2$ or $1 / 4$; one antigen fixed complement completely only after it had been concentrated twofold by centrifugation. In the tests each antigen was used at its optimum dilution. 


\section{RESULTS}

\section{Cultural characters of $\boldsymbol{P}$ and $\boldsymbol{S}$ strains}

Many strains of pleuropneumonia-like organisms were isolated from a large number of cattle, but technical difficulties made it impossible to maintain and investigate more than a selected few. It was soon noted that the majority produced peculiar and characteristic effects when grown on horse serum media; others lacked this property. The two types of organism also differed in other respects, notably in nutritional requirements. Whereas the strains producing the peculiar changes in horse serum media needed serum for growth, the other strains grew well without it. For convenience the former are referred to as ' $P$ ' strains and the latter as ' $S$ ' strains.

The $\mathbf{P}$ strains grew satisfactorily with horse serum or human ascitic fluid, but irregularly with ox serum. They grew on rabbit serum media, only after gradual adaptation; strains varied in the ease with which they could be adapted.

The S strains grew well on solid media without serum, although serum was necessary for adequate growth in fluid media. They resembled the saprophytic members of the pleuropneumonia group in this respect and in their ability to grow at room temperature; no growth of $\mathbf{P}$ strains occurred at this temperature. When grown in the presence of horse serum the $S$ strains produced none of the peculiar changes in the medium (see below) always produced by $\mathbf{P}$ strains.

$\mathbf{P}$ and $\mathbf{S}$ strains produced haemolysis when grown as deep colonies in the special horse serum medium containing $5 \%(\mathrm{v} / \mathrm{v})$ defibrinated blood. Saprophytic sewage organisms produced similar haemolysis. Haemolysis was obtained with human, horse, ox, sheep and rabbit blood. Haemolytic colonies of pleuropneumonia-like organisms were seen in pour-plates of ordinary blood agar, used to isolate and diagnose Corynebacterium pyogenes in vaginal discharges. The colonies could be easily distinguished under a magnification of $\times 10$; colonies of pleuropneumonia-like organisms were small, translucent and circular, and those of $C$. pyogenes opaque and irregular.

\section{Changes in horse serum media produced by $\boldsymbol{P}$ strains}

All $\mathbf{P}$ strains produced characteristic effects when grown on horse serum media. On solid media, after c. 4 days' incubation a greyish white film appeared over the surface of the heavily inoculated portion of an agar-plate culture; this could easily be seen by the naked eye (PI. 1, fig. 1). When examined with the dissecting microscope (magnification $\times 10$ ) this film appeared crinkled and extended between the colonies of the organism; there were also numerous small black dots in the upper layer of the medium both beneath the colonies and a few millimetres away, suggesting that they had been caused by a substance diffusing from the colony (Pl. 1, fig. 2). Fluid cultures developed an opalescence denser than is usual from the growth of a pleuropneumonia-like organism. Dark-ground microscopy revealed numerous relatively highly refractile masses in addition to the typical pleomorphic elements of the organism. They were mostly c. $4 \mu$ in diameter; sometimes they were smaller and more loosely constructed, when they appeared to consist of separate elements, whose shape it 
was difficult to determine. One or more spherical masses were sometimes seen in clumps of growth, as if they had developed inside the colony. They stained neutrophilic by Giemsa's method (Pl. 1, fig. 4).

These appearances were seen only in media containing horse serum; they were absent from cultures enriched with human ascitic fluid or rabbit serum. Even after repeated cultivation on media without horse serum the $\mathbf{P}$ strains did not lose their ability to cause the characteristic effects when again grown in the presence of horse serum. There was no evidence that the changes in the medium represented the growth of another living agent apart from the pleuropneumonia-like organism. These changes appeared to result from the precipitation of some substance in the medium during growth; the exact nature of this substance was not determined, although it is probably protein. The spherical masses seen in fluid media did not dissolve in fat solvents or in weak acid.

Ledingham (1938) described what he regarded as crystal formation in both plate and fluid cultures of the organism of agalactia. His photograph of a surface culture shows black dots in the medium similar to those produced by the $\mathbf{P}$ strains; he does not mention, however, a film on the surface of the plate. I have been unable to examine a culture of agalactia in comparison with the $P$ strains. Similar appearances on horse serum media were produced by a culture of the L 3 organism, but have not been seen in cultures of many strains of other members of the pleuropneumonia group that have been at one or other time investigated in this laboratory. They thus assist the identification of $\mathbf{P}$ strains.

\section{Serology of $\boldsymbol{P}$ and $\boldsymbol{S}$ strains}

Three $\mathbf{P}$ strains, differing antigenically, were investigated in detail. The results of agglutination and complement-fixation tests are shown in Table 1. Strains 2 and 14 were agglutinated to titres of $1 / 2048$ and $1 / 8192$ by their respective antisera, but neither was agglutinated by the heterologous antiserum. Strain 17 proved to be less specific. It was agglutinated by its homologous antiserum to a titre of $1 / 512$ and also by antisera 2 and 14 to $1 / 8$ and $1 / 32$ respectively of their full titres. Antiserum 17 did not agglutinate strain 14, although it agglutinated strain 2 to full titre.

Table 2. Results of absorbing Strain 17 rabbit antiserum

Strain 17 antiserum absorbed by strain

$\begin{array}{rrccc}\text { Antigen } & \text { Nil } & 2 & 14 & 18 \\ \text { Strain 17 } & 512 & 320 & 320 & 20 \\ 2 & 512 & <20 & - & - \\ 14 & <4 & - & <20 & - \\ 18 & 512 & - & - & <20\end{array}$

Although strain 17 was agglutinated by antisera 2 and 14, it proved to have a specific antigen by agglutinin-absorption tests (Table 2). After being absorbed twice with a heavy suspension of strain 2 the antiserum 17 no longer agglutinated strain 2 at a dilution of 1/20, but agglutinated strain 17 to the 


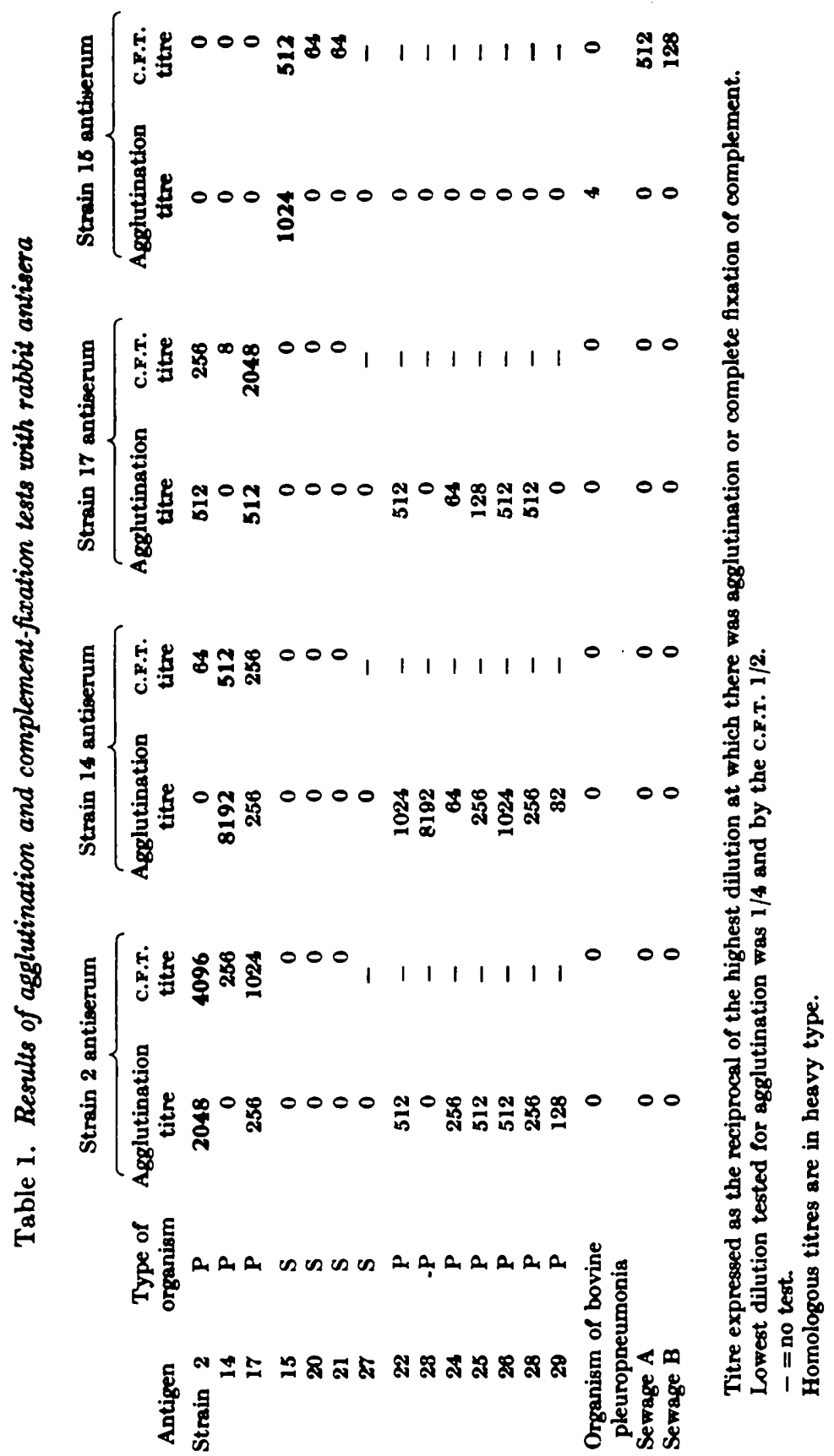


original titre. Similarly, adsorption with strain 14 did not affect its ability to agglutinate strain 17. On the other hand, strain 18, isolated from another animal in the same herd from which strain $\mathbf{1 7}$ had been isolated, almost completely removed the agglutinins for strain 17 .

Although strains 2 and 14 were antigenically distinct by the agglutination test, in the complement-fixation tests (C.F.T.) there were cross-reactions suggesting common antigens (Table 1). There was no correspondence between the magnitude of the agglutination and C.F.T. titres of the antisera for their homologous organisms. For instance, the agglutination titre of antiserum 14 was 16 times the C.F.T. titre, whereas antiserum 17 had an agglutination titre onequarter of the C.F.T. titre. There may, therefore, possibly be differences between the antigens concerned in the two types of test. No soluble complement-fixing antigens were demonstrable in filtrates of cultures.

Seven other $\mathbf{P}$ strains were tested with the three $\mathbf{P}$ antisera (Table 1 ). Strain 23 was agglutinated to full titre by strain 14 antiserum only; strains 23 and 14 thus appeared to be of the same serological type, although they were isolated from animals in different herds. On the other hand, although strains 23 and 26 were isolated from two animals in the same herd they were apparently different antigenically. Strain 28 gave the same reactions as strain 17. Strain 29 was not agglutinated to significant titre by any of the antisera. Most of the others were agglutinated by all three antisera, usually only to partial titre. Two went to full titre with antiserum 17, but, since this antiserum tended to be non-specific their identity remained uncertain. The serology of the $\mathbf{P}$ strains is therefore complex. A number of different serological types appear to exist, but certain antigens are shared.

Four S strains were tested against an antiserum to the $S$ strain 15 . They were not agglutinated and did not fix complement with any of the $\mathbf{P}$ antisera; nor did antiserum 15 agglutinate or fix complement with any of the $P$ strains (Table 1). The $\mathbf{P}$ and $\mathbf{S}$ types of organism are therefore serologically distinct. Antiserum 15, although agglutinating its homologous organism, did not agglutinate the other three $S$ strains; however, with the two strains tested it did fix complement to about $1 / 10$ of the full titre. Strains of the $S$ type thus differ antigenically among themselves although certain antigens are shared.

It was not possible to compare the antigenic constitution of these organisms with that of all the other members of the pleuropneumonia group. However, certain serological relationships were explored, namely, those of the $\mathbf{P}$ strains with the organism of contagious bovine pleuropneumonia (the only other member of the group previously isolated from cattle) and of the $S$ strains with the saprophytic organisms. The organism of bovine pleuropneumonia was not agglutinated by any of the antisera, except to a titre of $1 / 8$ only by the $S$ antiserum. The $\mathbf{P}$ strains are thus unrelated antigenically to the strain of the organism of bovine pleuropneumonia tested (no. 3278, National Collection of Type Cultures); of course this organism differs also in pathogenicity and does not produce the changes in media containing horse serum which are characteristic of $\mathbf{P}$ strains. Suspensions were prepared from two of Laidlaw \& Elford's (1936) strains, Sewage $A$ and $B$, which are antigenically different although 


\section{Pleuropneumonia-like organisms from cattle}

related; the third strain, Sewage $\mathrm{C}$, a distinct serological type, was unfortunately no longer available. Klieneberger (1940), using the agglutination test, showed that Seiffert's strains were closely related to Sewage A. Neither the $\mathbf{P}$ antisera nor the $\mathbf{S}$ antiserum agglutinated the sewage organisms, but the $\mathbf{S}$ antiserum fixed complement to full titre with Sewage $\mathbf{A}$ and to partial titre with Sewage $B$.

Table 3. Results of complement-fixation tests on sera from infected cattle

\begin{tabular}{|c|c|c|c|c|c|c|}
\hline \multirow[b]{2}{*}{ Animal } & \multicolumn{5}{|c|}{$\begin{array}{c}\text { Serum + antigen }+ \text { complement } \\
\text { Serum dilutions }\end{array}$} & \multirow{2}{*}{$\begin{array}{c}\text { Serum + saline }+ \\
\text { complement } \\
\text { Serum dilution } \\
\frac{1}{2}\end{array}$} \\
\hline & $\frac{1}{2}$ & $\frac{1}{4}$ & $\frac{1}{8}$ & $\frac{1}{18}$ & $\frac{-1}{38}$ & \\
\hline Cow 1 & 4 & 4 & 1 & $\mathbf{0}$ & $\mathbf{0}$ & $\mathbf{0}$ \\
\hline 2 & $\mathbf{3}$ & $\mathbf{3}$ & 3 & 2 & $\mathbf{0}$ & $\mathbf{0}$ \\
\hline $\mathbf{3}$ & $\mathbf{3}$ & $\mathbf{0}$ & - & - & - & o \\
\hline 4 & $\mathbf{3}$ & $\mathbf{2}$ & - & - & - & o \\
\hline 5 & 0 & o & - & - & - & o \\
\hline 6 & 1 & \pm & - & - & - & o \\
\hline 7 & 1 & $\overline{0}$ & - & - & - & $\mathbf{0}$ \\
\hline 8 & 4 & $\mathbf{0}$ & - & - & - & o \\
\hline Bull 1 & $\mathbf{0}$ & $\mathbf{0}$ & - & - & - & $\mathbf{0}$ \\
\hline 2 & 2 & 1 & - & - & - & o \\
\hline $\mathbf{3}$ & 4 & 4 & - & - & - & $\mathbf{0}$ \\
\hline 3 (repeat) & 2 & 1 & 2 & $\mathbf{0}$ & $\mathbf{0}$ & $\mathbf{0}$ \\
\hline
\end{tabular}

$4=$ complete fixation; 3 to $1=$ degrees of incomplete fixation; $\pm=$ trace of fixation only; $0=$ no fixation; $-=$ no observation made.

Suspension of ' $P$ ' strain 17 used undiluted as antigen. Control tube containing antigen, saline and complement showed no fixation.

Serological tests of bovine sera. Sera from twelve infected cows and bulls from which pleuropneumonia-like organisms had been isolated were tested for agglutinins. The titres obtained did not differ significantly from those of sera from normal maiden heifers. A few of the cattle sera were tested against a suspension of the organism isolated from that particular animal or from another in the same herd.

The sera were also tested for complement-fixing antibodies. Using the $\mathbf{P}$ strain 17, three sera fixed complement completely in low dilutions and several others gave partial fixation (Table 3). Under these conditions there was no fixation of complement by eight sera from normal maiden heifers. The results were confirmed with other antigens. For the tests the sera were inactivated by heating to $62^{\circ}$ for $30 \mathrm{~min}$., and this temperature was found to be essential for the specificity of the test. When inactivated at $56^{\circ}$ the infected sera showed a greater degree of fixation, but one of the control sera was also positive.

In an investigation of non-specific urethritis in man, Johnston \& McEwin (1945) isolated pleuropneumonia-like organisms from the discharges of two patients. When saline suspensions of the organisms were injected intradermally both patients gave positive skin reactions. A group of eight cows and one bull, from which pleuropneumonia-like organisms had been isolated, was therefore skin-tested. Saline suspensions of a $\mathbf{P}$ strain, prepared from a culture in sloppy agar, were injected intradermally together with a control injection of material 
similarly prepared from uninoculated culture medium. The skin reactions to the test inocula were no larger than those to the controls.

\section{DISCUSSION}

Two members of the pleuropneumonia group, provisionally called $\mathbf{P}$ and $\mathbf{S}$, have been isolated from the genital tract of cattle. The cultural similarities and the presence of common complement-fixing antigens suggest the $\mathbf{S}$ strains to be closely related to the saprophytic organisms. S organisms are therefore unlikely to be pathogenic for cattle; they may inhabit the genital tract as commensals or, alternatively, live in the environment of the animals, from which they gain access to the vaginal discharges and semen as contaminants.

The $\mathbf{P}$ strains are of greater interest, and it is important to determine whether they are pathogenic for cattle. Investigations in progress, which suggest that these strains are pathogenic and capable of producing inflammatory changes in the genital tract, possibly predisposing to infertility, will be described elsewhere. In an examination of a small number of sera from infected animals for specific antibodies a failure to demonstrate agglutinins is recorded here, although a few of the sera appeared to fix complement specifically. The examination of a larger number of sera from infected and non-infected animals would be necessary before the specificity of the complement-fixation reaction could be assumed and the presence of complement-fixing antibodies adduced as evidence of actual infection by pathogenic organisms. Beveridge, Campbell \& Lind (1946) found complement-fixing antibodies for a pleuropneumonia-like organism, isolated from the human genital tract, in 79 out of a group of 128 sera from cases of non-specific urethritis in man. Some doubt, however, as to the specificity of the test was raised by finding 7 out of 98 sera from healthy blood donors positive and 17 positive out of 24 from a group of cases of atypical pneumonia. Wallerstein, Vallee \& Turner (1946) obtained positive complement fixation in two cases of Reiter's disease. Harkness \& Henderson-Begg (1948), however, failed to demonstrate either complement-fixing antibodies or agglutinins in non-specific urethritis. Although information regarding the development of antibodies in animals infected by members of the pleuropneumonia group is incomplete, it would appear that agglutinins are demonstrable only irregularly even in contagious bovine pleuropneumonia (Sabin, $1941 a$ ). Neutralizing antibodies were not found in the sera after recovery from certain pleuropneumonia-like infections of mice (Sabin, 1938) and rats (Woglom $\&$ Warren, 1938). The absence of agglutinins in the sera of cattle from whom $P$ strains were isolated is therefore itself not evidence that the organisms were not pathogenic.

The demonstration that different serological types occur among the strains is of obvious importance in epidemiological and other studies; it is even possible that serological types may differ in their pathogenicity. Of greater significance was the finding that at least two different members of the pleuropneumonia group, one of which is probably non-pathogenic, can be isolated from the genital tract of cattle. Already there have been several examples of the importance of identifying a strain as a $\mathbf{P}$ or $\mathbf{S}$ type. For instance, at an early stage in the 
investigation it was realized that most of the material examined and found to contain pleuropneumonia-like organisms came from herds under observation for breeding difficulties. Semen was therefore examined from the stock bull in a herd with a good breeding history. The finding in it of pleuropneumonia-like organisms was at first disappointing; only later was the strain recognized as an $\mathrm{S}$ type. On another occasion samples were received from two bulls in a herd where there were breeding troubles apparently of infective aetiology. Pleuropneumonia-like organisms were present in both, but not other bacteria of pathogenic significance. Each sample was inoculated into the uterus of a healthy maiden heifer at oestrus. One sample, which was shown to contain a $\mathbf{P}$ organism, produced inflammation of the genital tract in the inoculated animal. The other sample contained an $S$ organism, and no ill-effect resulted from its inoculation. This experiment (together with others to be reported elsewhere) suggests that $\mathbf{P}$ strains may be pathogenic and $\mathbf{S}$ strains harmless. The isolation of both $\mathbf{P}$ and $\mathbf{S}$ organisms from animals in one herd emphasizes the need for the exact identification of every strain isolated.

$\mathbf{P}$ strains differed in the ease with which they grew in artificial culture; sometimes the colonies were poorly developed in the primary cultures and occasionally it was difficult or impossible to obtain subcultures. Some of the strains more difficult to grow came from animals in which there seemed to be greater evidence for the infectivity of the organism. Dienes, Ropes, Smith, Madoff \& Bauer (1948) had rather similar experiences in their investigation of pleuropneumonia-like organisms from the human genital tract. Strains isolated from the male grew poorly and were often difficult to subculture, whereas strains were easier to isolate from the female. In the female it was evident that many strains, at least, were not pathogenic, but in the male there was evidence that the organisms were producing inflammation. It is therefore possible that the ability of a strain to grow in artificial culture may vary inversely with its pathogenicity. Growth in the primary culture may be aided by factors supplied in the heavy inoculum of vaginal mucus or semen, and successful maintenance in subculture may depend on the formation of non-pathogenic variants capable of growth in an artificial culture medium. If this is so the strains maintained and studied in the laboratory are not truly representative of those present in the genital tract.

Experience in cattle may help in assessing the significance of pleuropneumonia-like organisms in the human genital tract. These organisms have been isolated from patients with non-specific urethritis by a number of observers but their pathogenicity is still in doubt. One objection to regarding them as pathogenic has been their presence in the vagina of a high proportion of women, including those apparently healthy. This objection, however, appears to have little validity. At one time it might have been argued that, because streptococci could be found in the normal human throat, they could not be responsible for disease. Only as methods for bacteriological study advanced was it possible by morphological, cultural, biochemical and serological investigations, leading up to recognition of the ' $M$ ' substance, to identify virulent strains of pathogenic species, such as Streptococcus pyogenes Group A, among the whole group of 
Gram-positive cocci growing in chains. No investigations have been made of strains of pleuropneumonia-like organism isolated from the human genital tract beyond those necessary to identify them as members of the pleuropneumonia group from their morphological and colonial appearances; no serological differentiation has been attempted. Sabin was the first to show that more than one species could be found in the same situation; he isolated several strains with completely different pathogenic properties from the upper respiratory tract of mice (Sabin, 1939; Sabin \& Johnson, 1940). The finding of both a potentially pathogenic species and a saprophyte or commensal in the genital tract of cattle emphasizes the need for cultural and serological investigations of strains isolated from the human genital tract. Until these have been made a member of the pleuropneumonia group cannot be excluded as a possible cause of some of the infections in man diagnosed as non-specific urethritis.

Names have not been given to the two members of the pleuropneumonia group isolated from cattle. The major differences in their cultural properties and their antigenic dissimilarity suggest that they represent different species. Sabin $(1941 a, b)$ has, in fact, suggested that the saprophytic pleuropneumonialike organisms should be classified in a different family from those organisms needing media enriched with animal protein for artificial cultivation. Final agreement has, however, not been reached regarding the nomenclature of the pleuropneumonia group. It would seem impossible to decide on a classification until members of the group have been studied in greater detail; further information regarding their cultural, biochemical and serological properties and their nutritional requirements is particularly required. There is even much which is still controversial regarding their morphology, although this has been studied most. The term 'pleuropneumonia-like organism' has therefore been used, and the two species have been provisionally referred to by the letters $\mathbf{P}$ and $\mathbf{S}$. Members of the group are sometimes called $L$ organisms, but this designation has been avoided because, although shorter, it refers merely to the serial numbering of species isolated by one worker in this country.

Note. Investigations of the pleuropneumonia group have been hindered by the difficulty in maintaining strains, which has resulted in many, originally isolated in this country, being lost. Mr H. Proom has successfully preserved strains by freeze-drying and has undertaken to maintain a representative collection of these organisms at the Wellcome Research Laboratories, Beckenham, Kent, for the use of other investigators.

I am indebted to my colleagues, Mr S. L. Hignett and Mr J. L. Hancock, for carrying out the inoculations of cattle, and to Mr E. A. Jones and Mr E. Hitchcock, of the Wellcome Research Laboratories, Beckenham, for taking the photomicrographs.

\section{REFERENCES}

Beveridge, W. I. B., Campbell, A. D. \& Lind, P. E. (1946). Pleuropneumonia-like organisms in cases of non-gonococcal urethritis in man and in normal female genitalia. Med. J. Aust. 1, 179.

DIENEs, L. (1947 a). Isolation of pleuropneumonia-like organisms from pathological specimens with the aid of penicillin. Proc. Soc. exp. Biol., N.Y., 64, 165.

DIENEs, L. $(1947 b)$. Isolation of pleuropneumonia-like organisms from $H$. influenzae with the aid of penicillin. Proc. Soc. exp. Biol., N.Y., 64, 166. 
Journal of General Microbiology, Vol. 4, No. 1

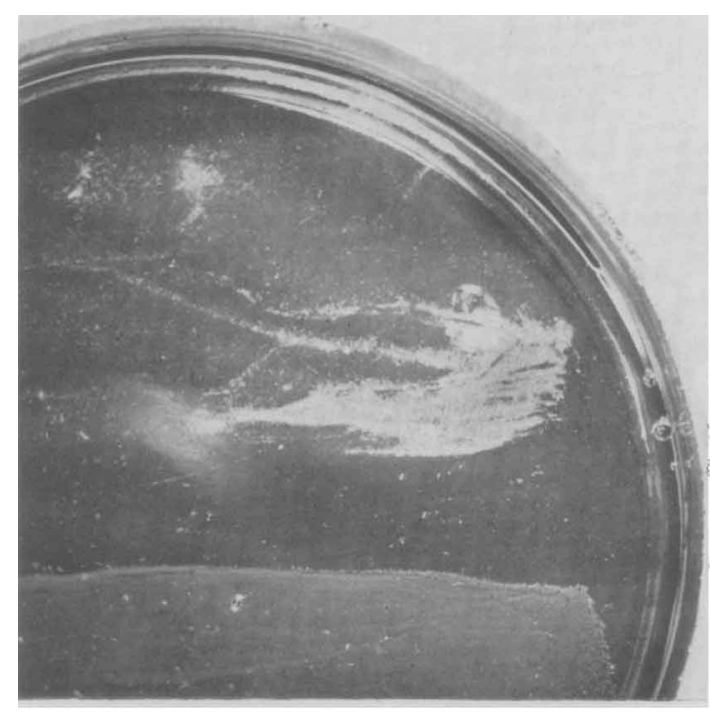

Fig. 1

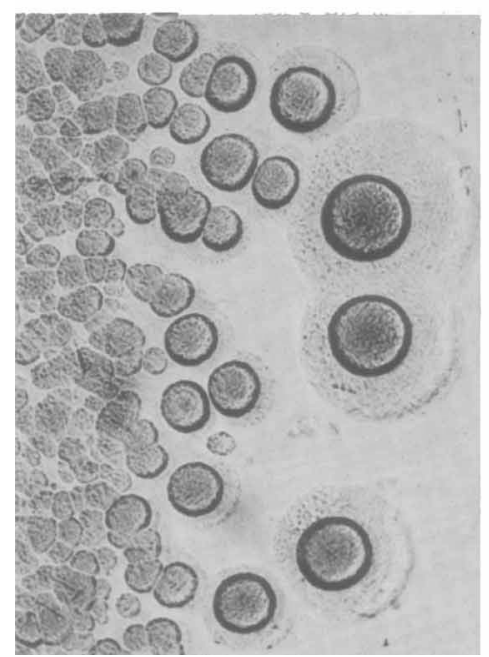

Fig. 3

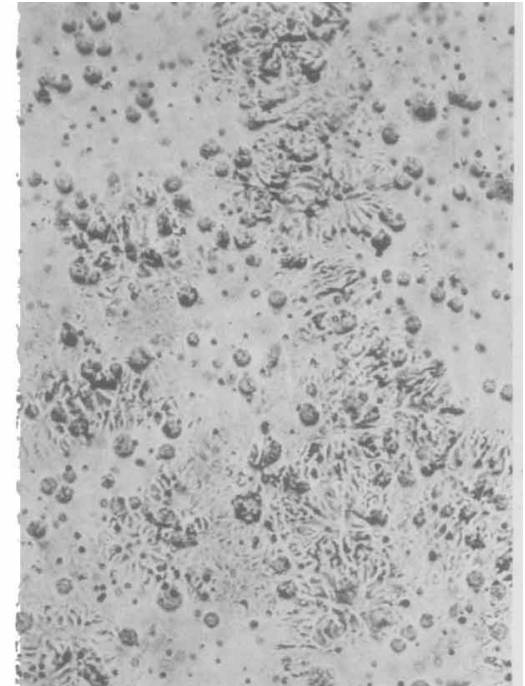

Fig. 2

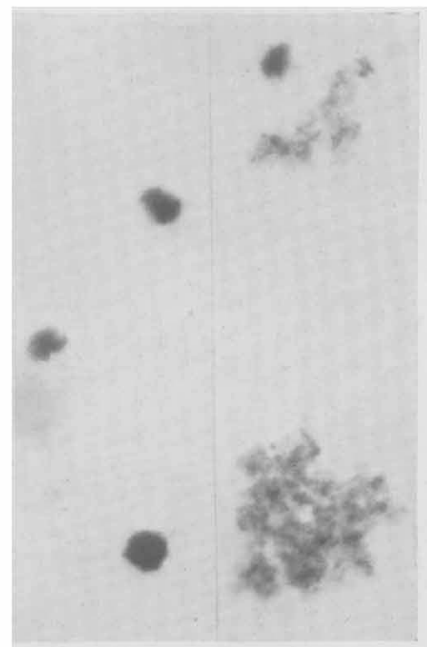

Fig. 4

D. G. Ff. Edward-Investigation of Pleuropneumonia-like onganisms. Plate 1 


\section{Pleuropneumonia-like organisms from cattle}

Dienes, L., Ropes, M. W., Smith, W. E., Madoff, S. \& Bauer, W. (1948). The role of pleuropneumonia-like organisms in genitourinary and joint diseases. New Engl. J. Med. 238, 509, 563.

EDWARD, D. G. FF. (1947). A selective medium for pleuropneumonia-like organisms. J. gen. Microbiol. 1, 238.

Edward, D. G. FF., Hancock, J. L. \& Hignett, S. L. (1947). Isolation of pleuropneumonia-like organisms from the bovine genital tract. Vet. Rec. 59, 329.

Harkness, A. H. \& Henderson-Begg, A. (1948). The significance of pleuropneumonia-like or ' $L$ ' organisms in non-gonococcal urethritis, Reiter's disease and abacterial pyuria. Brit. J. ven. Dis. $24,50$.

Jornston, G. A. W. \& McEwIN, J. (1945). Non-gonococcal arthritis. Med. J. Aust. 1, 368.

Kutengberger, E. (1938). Pleuropneumonia-like organisms of diverse provenance: some results of an enquiry into methods of differentiation. J. Hyg., Camb., 38,458.

KuIENEBERGER, E. (1940). The pleuropneumonia-like organisms : further comparative studies and a descriptive account of recently discovered types. J. Hyg., Camb., 40, 204.

Lamblaw, P. P. \& Elford, W. J. (1936). A new group of filtrable organisms. Proc. Roy. Soc. B, 120, 292.

LeDINGHAM, J. C. G. (1933). The growth phases of pleuropneumonia and agalactia on liquid and solid media. J. Path. Bact. 37, 393.

Rrchardson, G. M. (1941). Preservation of liquid complement serum. Lancet, ii, 696.

SABIN, A. B. (1938). Isolation of a filtrable, transmissible agent with 'neurolytic' properties from toxoplasma-infected tissues. Science, 88, 189.

SABIN, A. B. (1939). Mice as carriers of pathogenic pleuropneumonia-like microorganisms. Science, $90,18$.

Sabin, A. B. (1941 a). The filtrable micro-organisms of the pleuropneumonia group. Bact. Rev. 5, 1:

Sabin, A. B. (1941b). The filtrable micro-organisms of the pleuropneumonia group. (Appendix on classification and nomenclature.) Bact. Rev. 5, 331.

Sabin, A. B. \& Johnson, B. (1940). Pathogenic pleuropneumonia-like microorganisms in tissues of normal mice and isolation of new immunological types. Proc. Soc. exp. Biol., N.Y., 44, 569.

SeIfFert, G. (1937a). Ueber das Vorkommen filtrabler Mikroorganismen in der Natur und ihre Züchtbarkeit. Zbl. Bakt. (1 Abt., Orig.), 139, 337.

SeIFFert, G. (1937b). Filtrable Mikroorganismen in der freien Natur. Zbl. Bakt. (1 Abt., Orig.), 140, 168.

Wallerstein, R., Vallee, B. \& Turner, L. (1946). The possible relationship of pleuropneumonia-like organisms to Reiter's disease, rheumatoid arthritis and ulcerative colitis. $J$. infect. Dis. 79, 134.

Woglom, W. H. \& WARren, J. (1938). A pyogenic filtrable agent in the albino rat. J. exp. Med. 68, 513.

\section{EXPLANATION OF PLATE}

Fig. 1. Cultures on horse serum agar plate. Upper portion seeded with ' $P$ ' strain; note white film covering bottom right portion of growth; colonies too small to be seen individually. Lower portion of plate seeded with ' $S$ ' strain; no film.

Fig. 2. Surface culture of ' $P$ ' strain seen by transmitted light; note small colonies of organism, in places covered by a crinkled film, also numerous small black dots. $\times 85$.

Fig. 3. Surface culture of ' $S$ ' strain for comparison. Colonies large and typical of the pleuropneumonia group; no surface film or black dots in the medium. $\times 85$.

Fig. 4. Film made from the deposit of a horse serum broth culture of $a$ ' $P$ ' strain and stained by Giemsa. Two parts of the same field showing on the right two clumps of the organism and on the left characteristic bodies. $\times 2000$.

(Received 23 February 1949) 